\title{
Low Cost, Quality Treatment and Excellent Hospitality Makes India the Best Destination for Medical Tourism
}

\author{
Dr Ruchi Garg, Rahul Batra, Anirudh Banerji \\ ${ }^{1}$ Asst. Professor, Department of Hospital Administration, Mahatma Gandhi University of Medical Sciences and \\ Technology, Jaipur, 302022, India \\ ${ }^{2}$ Business Analytics, Motherhood Hospitals, Bangalore, 560001, India \\ ${ }^{3}$ Senior Project manager Medica Super Specialty Hospital, Kolkata, 700075, India
}

Corresponding Author: Rahul Batra; rahulbatra253@gmail.com

Received: 16 April 2019

Accepted: 22 December 2019

Published 10 January 2020

\begin{abstract}
Background: Medical Tourism can be defined as the provision of cost effective private medical care in collaboration with the tourism industry for patients needing surgical and other forms of specialized treatment. India stands and leads in the field of medical tourism. This sector has grown rapidly in last few years and have been known by number of countries for its sudden advancement in the field of healthcare, although India is still competing with neighbouring countries which already have a good hold of this market. India offers trained workforce and culture diversity as well as experienced doctors who have names in the list of Padma-Shri awardees in honour of their excellence in the field of health. Methods: The study was conducted in a Super Speciality Hospital in Gurugram for two months, being retrospective and descriptive in nature. Secondary data was taken for the month of January 2018 to March2018 and data for April and May 2018 was recorded during the study, a group of 50 patients, selected randomly, were asked for their feedback to know the strengths of medical tourism as well as for the improvement in the hospital. Results: This paper focuses on the process of medical tourism followed in India and the flow of medical tourists traveling to India for their treatment from various countries as well the catchment areas of patient coming to a Super Speciality Hospital in Gurugram. Conclusions: The paper concludes the strengths of developing country like India which attracts many medical tourists from various regions.
\end{abstract}

Keywords: Medical Tourism, Surgical, Advancement, Catchment areas, Cost Effective.

\section{Introduction}

Medical tourism ${ }^{[1]}$ is an act wherein foreign patients travel across to other countries in order to avail better health facilities to avail an economic cost. This activity is also known as wellness tourism and it is seeing rapid growth as people across the globe are traveling to different countries to get themselves treated in hospitals offering better Medical, surgical, or dental care while also touring, vacationing and exploring the ancient history of the countries they are visiting. Medical tourism is an opportunity for patients to travel for medical and quality care and to take the benefit of reduced costs as well as waiting time. In simple words, the medical tourism refers to "visit by International patients for medical Treatment and care and relaxation". With countries like India, Mexico, Singapore, Brazil, Argentina, Greece, Costa Rica, Dominican Republic, Peru, Malaysia, South Africa, Thailand actively promoting it, the future of medical tourism is very bright. Medical tourists generally come from industrialized nations of the world and usually from countries like The United States, Canada, England, Parts of Europe, Australia ${ }^{[2]}$. But recent trends show that apart from focusing on health, people from different countries of the world are seeking out places where they can enjoy a vacation as well as obtain medical treatment at an affordable price. The increase in advancement in technology and medical researches, augmented product consciousness and globalization are the trends which are influencing most parts of the industry.

Medical Tourism agencies, or medical travel facilitator, are the firms that, as their name suggests, act as facilitators or middlemen for medical tourism patients engaging in medical tourism. Such facilitators act as a third party and have played an important role in promoting the growth of medical tourism. For many medical tourists, these facilitators have been the first face of contact with the concept of medical tourism.

India is renowned for ancient alternative therapies such as Ayurveda, Yoga, and Meditation and naturopathy and Gurugram has recently emerged as an important hub for medical tourism. Apart from being an IT hub and a favourite location for MNC firms, the city has several world class hospitals that not only treat Indian citizens but also people from outside the country ${ }^{[3]}$. Hospitals in Gurugram have specialities in various fields that 
attract most of the foreign patients for the treatment including offbeat areas of medicine like holistic treatment, dental surgery, cosmetics surgery, addiction treatment, hair transplant and so on ${ }^{[4]}$. Procedures like knee replacement, chemotherapy, Hip joint replacement and Lap band Surgery are successfully performed in
Gurugram hospitals. World Class Hospitals like Artemis, Medanta, the Medicity, Paras, Fortis and Max are well equipped to offer patients the desired treatment and nursing. So, this millennium city holds a lot of potential when it comes to offering medical care of international standards.

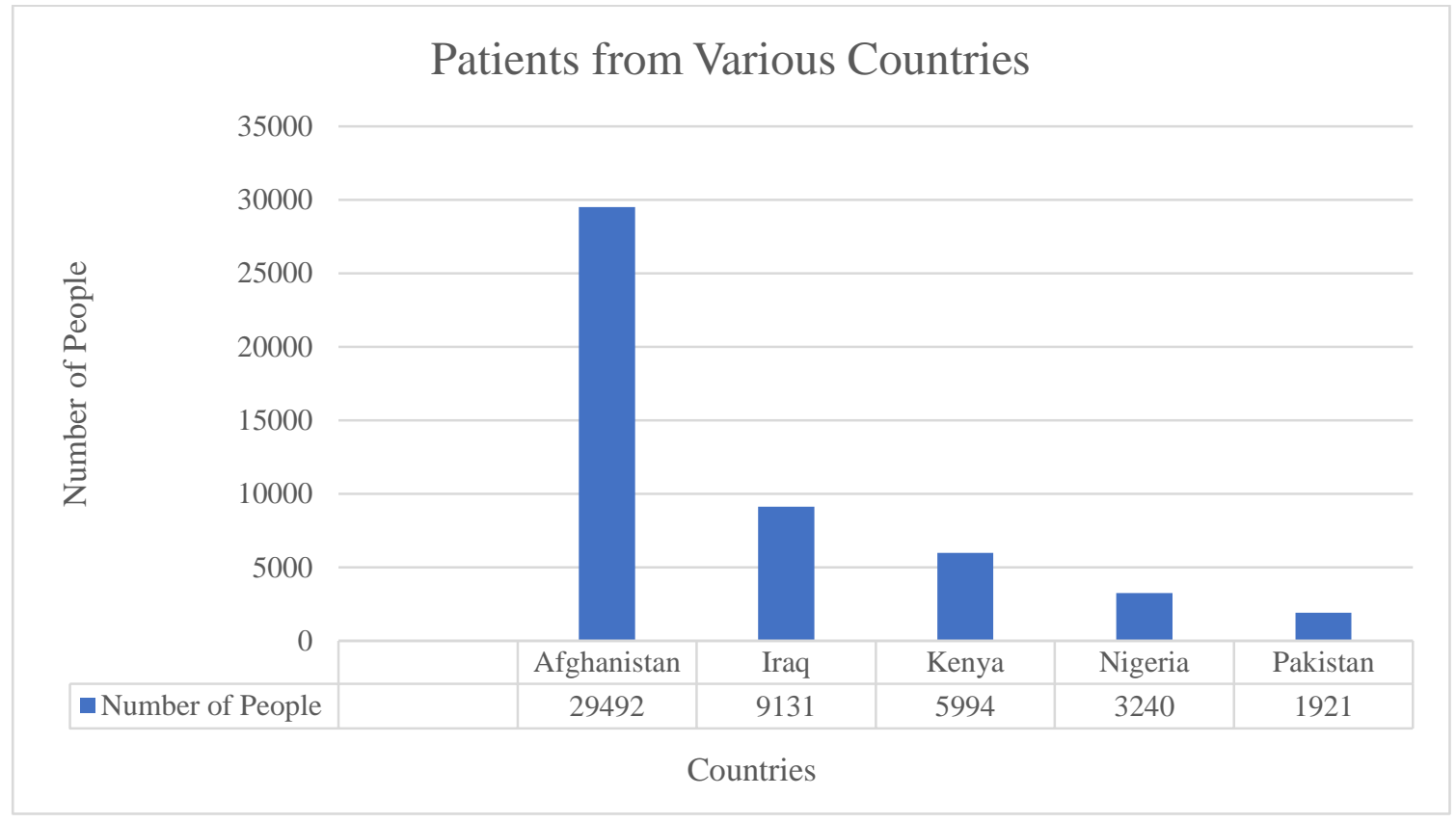

Number of Medical Tourists Opted for India for treatment in 2015-2016

Source: Report given on Export Health Services by the Directorate-General of Commercial Intelligence that shows Statistics of India for year 2015-2016.

\section{Objectives of the Study}

This research works explores the process of Medical Tourism in India and discusses the flow of patients in a super speciality hospital from the month of January 2018 to May 2018 from different countries, the various specialities sought and the catchment areas of medical tourists coming to the hospital for treatment. This research also emphasizes the strengths of medical tourism of India over other countries.

The study was conducted in a Super Speciality Hospital in Gurugram and was carried out for two months, being retrospective and descriptive in nature. Secondary data was taken from the hospital for the month of January 2018 to March2018 and data for April and May 2018was recorded during the study. During the study, a group of 50 patients, selected randomly, were asked for their feedback to know the strengths of medical tourism as well as for the improvement in the hospital.

\section{Limitations of the Study}

1) The present study was limited as the patient's data was confidential and only limited data is used for study purpose.

2) The scope of the present study is set only from the month of January 2018 to May 2018. 


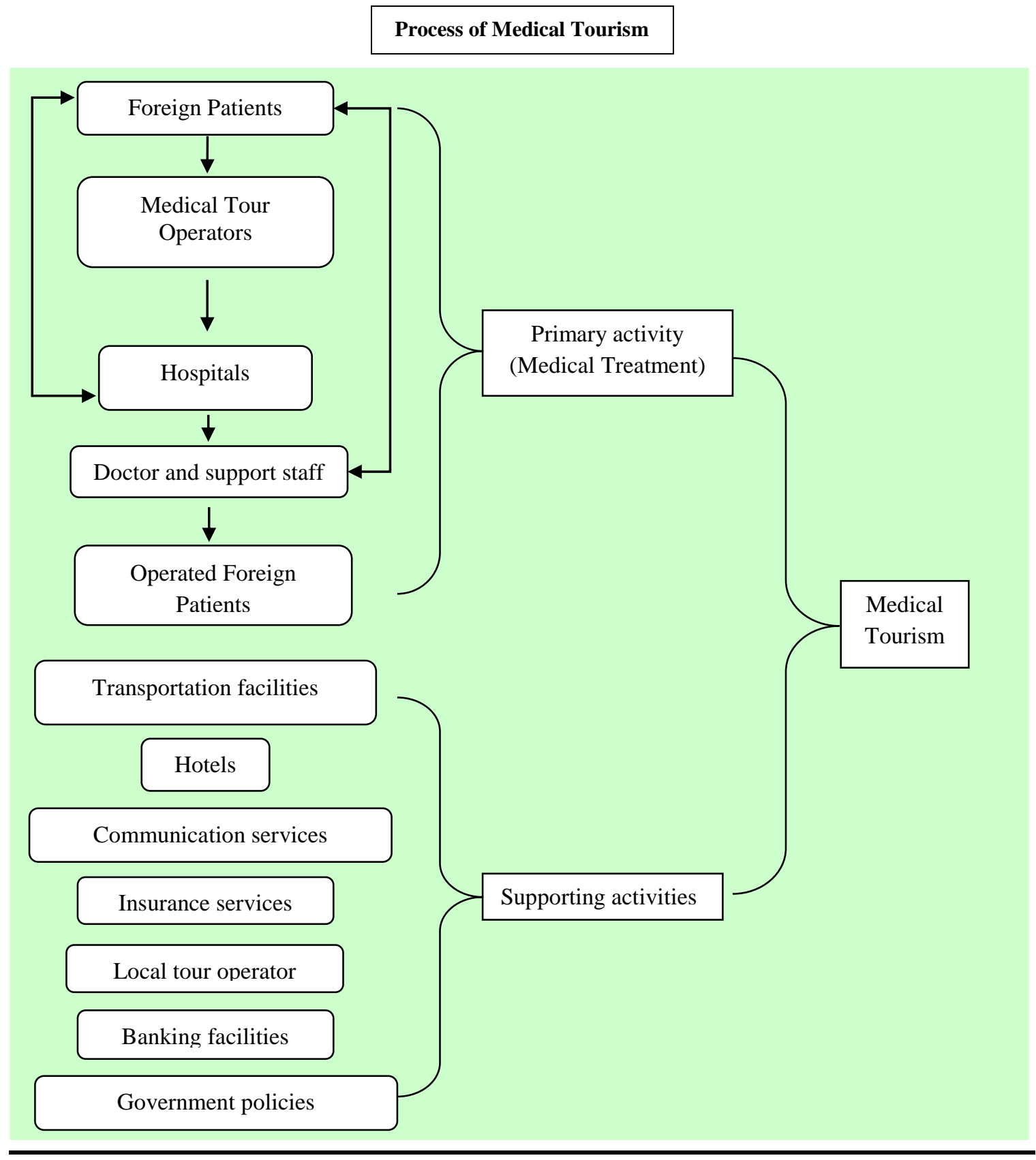

Medical tourism value chain starts when the attempt of availing the best and affordable medical facilities fails in their country and the patient tries for the other country. Foreign patients have two options- they can contact the medical tourism companies or can be in direct touch of hospital. Medical tourism companies provide comprehensive packages which include the medical and travel insurance and legal protocols if in case anything happens during the tour abroad or in the visa process and provides a healthcare facilitator. Foreign Patient can directly walk in and contact the healthcare service provider, which is the hospital, with their reports, review their medical history and get the treatment continued with the hospital with their own choice of doctors too. The medical referral companies use their knowledge of the medical community and institutions to ensure that the patient goes to a reliable medical facility with a proven track record of treating foreign patients. The hospital provides a medical visa to the patient who comes with his/her query to the hospital and is interested in availing the medical facilities of the hospital and the service of forex exchange also. Once the country is decided by foreign patient on their own or with the help of medical tourism company, other supporting requirements of the travel such as bank, hotels, embassies and visa arrangement etc are also worked out easily.
With the help of this chain of medical tourism, the country can earn and generate revenue for itself in terms of foreign exchange.

The Medical Tourism Company will inform the hospital through Pre-Facto mail which is used to give pre-intimation to the hospital before the patient comes to the hospital. Subsequently, the representative of the hospital goes to the airport to receive the patient. After receiving the patient, the patient is provided with the local sim card and then the formalities and their Identity proof and first-time registration will be completed by the hospital on the same day of arrival. Patient will be sent to the specialized doctor for the problem for which they have come to the hospital. There are chances that patients might be a cash patient, or a credit patient sponsored by the ministry of health of their respective countries. The treatment will get planned and all the necessary investigations will be completed from the side of the hospital. The Estimated cost already gets quoted by the hospital to the patient or medical tourism company or the Health Care Facilitator or the ministry of health before the patient travels to India.

After the treatment, the patient will be given a 'Fit to Fly Certificate' and all the arrangement will be done by the hospital or the medical tourism company and if the patient wish to enjoy 
scenic beauty of India in post recuperative holidays that can also be arranged by the tourism company or facilitator.

Table 1: Total number of international patient's - month wise (January 2018 May 2018)

\begin{tabular}{|l|c|}
\hline Month & No. of Patients \\
\hline January & 1057 \\
\hline February & 1189 \\
\hline March & 1325 \\
\hline April & 1252 \\
\hline May & 1238 \\
\hline Total & 6061 \\
\hline
\end{tabular}

The Inflow of International Patients shows a high increase in the month of February, followed by an increase in the month of March and then gradually decreases, The Inflow of International Patients was very high in the month of March.
Table 2: Total number of international patient's - country wise (January 2018 to May 2018)

\begin{tabular}{|l|c|}
\hline Country & Number of Patients \\
\hline Iraq & 3242 \\
\hline Afghanistan & 699 \\
\hline Nigeria & 340 \\
\hline Malawi & 287 \\
\hline Uzbekistan & 384 \\
\hline Turkmenistan & 357 \\
\hline Tajikistan & 118 \\
\hline Congo & 224 \\
\hline Others & 410 \\
\hline Total & 6061 \\
\hline
\end{tabular}

The inflow of International Patients is maximum from the Country of Iraq (3242) in which is followed by Afghanistan (679), Uzbekistan (384) and Turkmenistan.

Table 3: Total number of international patient's - speciality wise

\begin{tabular}{|l|l|l|l|l|l|l|}
\hline Speciality & Jan & Feb & Mar & Apr & May & Total \\
\hline Paediatrics & 15 & 18 & 19 & 10 & 16 & 78 \\
\hline Paediatric Cardiology & 21 & 17 & 17 & 19 & 16 & 90 \\
\hline Urology & 15 & 13 & 11 & 15 & 17 & 71 \\
\hline Other & 4 & 3 & 5 & 2 & 3 & 17 \\
\hline Cosmetics and Plastic Surgery & 14 & 13 & 11 & 12 & 16 & 66 \\
\hline Obstetrics and Gynaecology & 12 & 15 & 19 & 13 & 16 \\
\hline Surgical Oncology & 7 & 9 & 15 & 14 & 12 & 75 \\
\hline CTVS & 9 & 11 & 16 & 10 & 11 \\
\hline Nephrology & 17 & 15 & 19 & 18 & 22 & 57 \\
\hline Ophthalmology & 17 & 19 & 16 & 21 & 91 & 19 \\
\hline ENT & 19 & 23 & 20 & 26 & 13 \\
\hline General Surgery & 25 & 32 & 29 & 27 & 31 \\
\hline Internal Medicine & 42 & 46 & 43 & 48 & 53 \\
\hline Neurology & 52 & 63 & 76 & 82 & 69 \\
\hline Cardiology & 110 & 94 & 113 & 89 & 121 \\
\hline Neurosurgery & 143 & 172 & 182 & 153 & 190 \\
\hline Medical Oncology & 237 & 237 & 295 & 267 & 301 \\
\hline Orthopaedics & 298 & 389 & 419 & 426 & 312 \\
\hline Grand Total & 1057 & 1189 & 1325 & 1252 & 1238 \\
\hline
\end{tabular}

The maximum number of patients comes for the specialty of Orthopaedics followed by Medical Oncology, Neurosurgery, Cardiology, Neurology and so on.

Table 4: Catchment areas of international patients from the highest revenue generating countries in different speciality

\begin{tabular}{|l|l|l|l|l|l|}
\hline Country & January & February & March & April & May \\
\hline Iraq & Spine, Orthopaedics & $\begin{array}{l}\text { Orthopaedics, } \\
\text { Medical Oncology }\end{array}$ & $\begin{array}{l}\text { Paediatric Cardiology, } \\
\text { Orthopaedics }\end{array}$ & $\begin{array}{l}\text { Orthopaedics, } \\
\text { Cardiology }\end{array}$ & $\begin{array}{l}\text { Orthopaedics, Spine, } \\
\text { Medical Oncology }\end{array}$ \\
\hline $\begin{array}{l}\text { Africa } \\
\text { Nigeria) }\end{array}$ & $\begin{array}{l}\text { Bone Marrow } \\
\text { Transplant, Liver, } \\
\text { Spine }\end{array}$ & $\begin{array}{l}\text { Kidney Transplant, } \\
\text { Bone Marrow, } \\
\text { Orthopaedics }\end{array}$ & $\begin{array}{l}\text { Bone Marrow } \\
\text { Transplant, } \\
\text { Orthopaedics }\end{array}$ & $\begin{array}{l}\text { Paediatric } \\
\text { Cardiology, Liver, } \\
\text { Transplants }\end{array}$ & $\begin{array}{l}\text { Orthopaedics, } \\
\text { Nephrology }\end{array}$ \\
\hline \multirow{3}{*}{ Afghanistan } & $\begin{array}{l}\text { Paediatric Cardio, } \\
\text { Orthopaedics, } \\
\text { Medical Oncology }\end{array}$ & $\begin{array}{l}\text { Orthopaedics, } \\
\text { Cardiology, } \\
\text { Kidney Transplants }\end{array}$ & $\begin{array}{l}\text { Orthopaedics, Medical } \\
\text { Oncology }\end{array}$ & $\begin{array}{l}\text { Orthopaedics, } \\
\text { Internal Medicine, } \\
\text { Neurosurgery }\end{array}$ & $\begin{array}{l}\text { Neurosurgery, } \\
\text { Orthopaedics }\end{array}$ \\
\hline \multirow{2}{*}{ Uzbekistan } & $\begin{array}{l}\text { General Medicine, } \\
\text { Paediatric Cardiology }\end{array}$ & $\begin{array}{l}\text { Paediatric } \\
\text { Cardiology, } \\
\text { Radiation Oncology }\end{array}$ & $\begin{array}{l}\text { Paediatric Cardiology, } \\
\text { Neurosurgery }\end{array}$ & $\begin{array}{l}\text { Paediatric } \\
\text { Cardiology, } \\
\text { Physiotherapy }\end{array}$ & $\begin{array}{l}\text { Paediatric Cardiology, } \\
\text { Neurology, Bone } \\
\text { Marrow Transplant }\end{array}$ \\
\hline Turkmenistant, & $\begin{array}{l}\text { Hepatitis B, } \\
\text { Orthopaedics, Spine }\end{array}$ & $\begin{array}{l}\text { Hepatitis B, } \\
\text { Orthopaedics }\end{array}$ & $\begin{array}{l}\text { Medical Oncology, } \\
\text { Liver, Spine }\end{array}$ & $\begin{array}{l}\text { Kidney Transplant, } \\
\text { Orthopaedics }\end{array}$ \\
\hline \multirow{2}{*}{ Tajikistan } & $\begin{array}{l}\text { General Medicine, } \\
\text { Orthopaedics }\end{array}$ & $\begin{array}{l}\text { Cardiology, Internal } \\
\text { Medicine }\end{array}$ & $\begin{array}{l}\text { Oncology, General } \\
\text { Medicine }\end{array}$ & $\begin{array}{l}\text { Orthopaedics, Bone } \\
\text { Marrow Transplant }\end{array}$ & $\begin{array}{l}\text { Spine, Orthopaedics, } \\
\text { Transplants }\end{array}$ \\
\hline
\end{tabular}


The maximum number of people from Iraq comes for Orthopaedics Department. Many patients are from Africa for the Transplants of Liver or Kidneys, followed by Medical oncology and the others.

\section{SWOT of Medical Tourism in India}

\begin{tabular}{|c|c|}
\hline Strengths & Weakness \\
\hline $\begin{array}{l}\text { - Availability of Hospitals which are designed and constructed } \\
\text { with JCI guidelines. } \\
\text { - State-of-for different specialities and the presence of advance } \\
\text { healthcare system. } \\
\text { - Infrastructure and Quality of Experienced doctors and highly } \\
\text { supporting hospital staff with high reputation globally. } \\
\text { With no waiting lists, English-speaking employee base, Wide } \\
\text { Range of services and preference of choosing rooms, translator } \\
\text { and interpreter proves to be strength of Medical Tourism in India. }\end{array}$ & $\begin{array}{l}\text { - No Medico legal security for medical tourists } \\
\text { - } \quad \text { No support from the side of government for promoting medical } \\
\text { tourism. } \\
\text { - Language Problem sometimes is one of the common problems. } \\
\text { - Lack of uniformity in the pricing policies of different hospitals } \\
\text { - Customer perception as unhygienic country. } \\
\text { - Low Co-ordination between different stakeholders of the } \\
\text { industry. }\end{array}$ \\
\hline Opportunities & \\
\hline $\begin{array}{l}\text { - Range of Treatment and Services comparable to other Super } \\
\text { Speciality Hospitals lead to increase in demand from various } \\
\text { countries across the globe } \\
\text { - Demand from the countries with high elderly population. } \\
\text { - Cost of Treatment high in other countries is beneficial for Indian } \\
\text { Hospital, more CME and Camps can result in more patient } \\
\text { coverage from different countries. } \\
\text { - Increasing Demand from underdeveloped countries with less } \\
\text { healthcare facilities. } \\
\text { Involving Government in medical tourism can be beneficial in } \\
\text { process of visa and as well as inviting medical tourists from } \\
\text { various countries. }\end{array}$ & 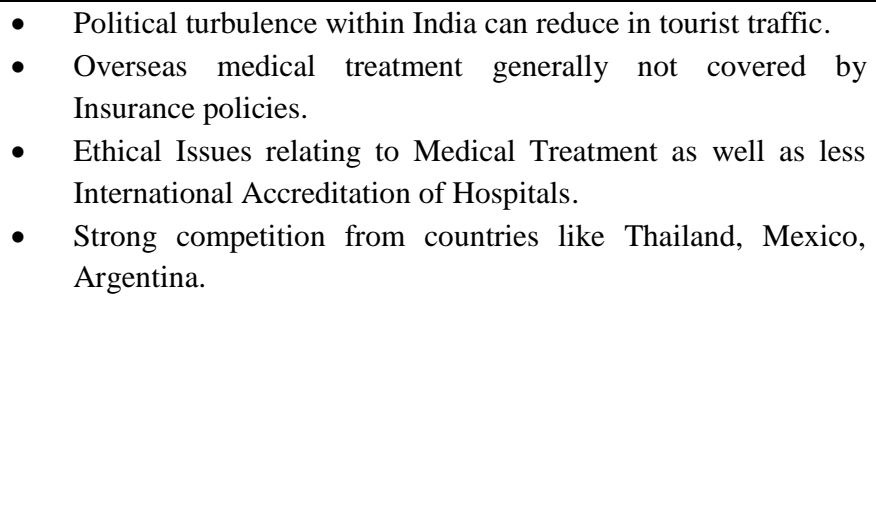 \\
\hline
\end{tabular}

\section{Discussion}

India has a good hold among medical tourists due to the advancement in the conditions of medical care and the availability of the trained workforce as well as the richness in the culture diversity, with the presence of experienced doctors who have names in the list of Padma-Shri awardees in honour of their excellence in the field of health. Factors that attract tourists to India are the quality care provided here as well as the advancement and reduced waiting time ${ }^{[5]}$, and the cost of treatment and medical care and major surgeries costs very less in compare to different hospitals of other countries like United States. India have specializations in Cosmetic Surgery, Dentistry, Ophthalmology, Orthopaedics as well as oncology treatments. To attract more tourists to India the hospitals here organise seminars and invite various leading professional from different hospitals and take part in medical research to come up with something new so that we can offer world best services within our premises only. Indian hospitals are rich with high end technology for various interventions such as Gamma knife, Cyber knife, IMRT, brain suite, Novelix TX, PET Scan, IGRT, etc. One of the advantages in choosing India for treatment is the acceptability of language as the rise in education and English being the most common language to communicate with everyone is one of the strengths of the healthcare providers in India. The doctors as well as nursing and para medical staff speaks fluent English ${ }^{[6,7]}$ The ancient ways of treatment still have strong belief in the minds of medical tourists which counts for the traditional way of providing medical care to the patients with the help of Ayurveda, Yoga, Meditation, and naturopathy. Apart from this, medical tourists are attracted to India because of its wonderful locations and when medical tourists visit India for treatment, they end up being going for visiting the country ${ }^{[8]}$.

Whereas on the other hand countries like Thailand having well established infrastructure and being an old player in the field of medical tourism is very much known for its beautiful locations. The largest private hospital of Asia is in Thailand and the country have 37hospitals accredited by Joint Commission International (JCI) ${ }^{[9]}$. Even Bangkok have become the centre for medical tourism as the city have its own health providing centres with 26 Different languages for different people from different countries. The flow of patients to Thailand is majorly from the parts of America. Thailand have specializations in Infertility, Ophthalmology, Bariatric Treatment as well as Medical Check-up Programmes. Mexico is also a key player in medical tourism which attracts large number of patients from parts of America, as Americans don't need visa, and travelling is easy for Americans as they can go back to home on the same day itself. Mexico have some of the best doctors for the Specialities like Cardiology, Dentistry, Cosmetic, and Plastic Surgeries and have the provision of day care surgeries too ${ }^{[10]}$. Argentina is very famous for its cosmetic treatment which costs half the price of the Countries like Germany and America, counts for $33 \%$ of total visitors to the country and for its dental implants. The country also provides Medical Malpractice Insurance which is a unique selling proposition for them, and the insurance can be claimed if in case anything goes wrong, it makes the whole process much cheaper and less stressful for the patient ${ }^{[11]}$.

\section{Conclusion}

Medical tourism is becoming an important fast driver for the growth of India tourism and of the healthcare industry. Medical Tourism is the process of travelling outside of the country for medical treatment and healthcare services. After conducting the study, it was found that many patients coming to the hospital belong to Iraq followed by Afghanistan, Nigeria, Malawi, Uzbekistan and few patients from Congo and other countries. Popular medical treatments undertaken by them are in the field of 
are orthopaedics, medical oncology, neurosurgery, and cardiology. Nephrology and CTVS are the upcoming specialities for which patients are seeking services. More patients are coming from Uzbekistan thus more focus can be given to get patients from that area. The key strengths are availability of hospitals JCI guidelines and the infrastructure and quality of experienced doctors with highly supporting hospital staff with high reputation globally, almost no waiting lists, English-speaking employee base, wide range of services proves to be strength of medical tourism in India $^{[12]}$.

\section{Recommendation}

Indian medical tourism sector should coordinate with other stakeholders to spread the awareness and remove existing barriers in the development of this sector. The joint platform of tourism, healthcare, aviation and information communication department should be integrated with each other for the medical tourists choosing India for their treatments. Hospital should work more on attracting patients from countries like United Kingdom and Australia, to develop more business and should do tie up with the insurance company's provider which counts for overseas treatment for patients. Hospital should participate in exhibitions related to Medical Tourism to cap opportunities to cover more countries and build network with healthcare facilitators. Post-Discharge tele consultation and follow up with the treating doctor should be frequent, more number payment options and gateways should be accepted to save the time. Although India is known for providing high quality, low cost treatment, and working on established protocols as well as following the standards, a lot is required to create uniformity in pricing policies. There have been instances where, due to different pricing policies, the cost of treatment has escalated after the patient travelled to the country of medical treatment. A uniform pricing policy is required to maintain the flow of patients. Apart from this, political turbulence as well as other vulnerable factors like terrorist attacks in different parts of nation affects medical tourism. Inbound patients travelling to other countries for medical treatment should be the given the facility of visa on arrival in order to reduce the time span of the process.

\section{Conflicts of Interest}

Nil

\section{Funding Statement}

No funding has been done by any of the governing body.

\section{Acknowledgement}

1) I would like to express my deep and sincere gratitude to my mentor Dr Ruchi Garg for providing valuable guidance throughout this research. Her dynamism vision sincerity and motivation have deeply inspired me. It was great privilege and honour to study under her guidance.

2) I would like to thank Dr Aihatram Khan for helping me out during this study.

\section{References}

[1] Das R. Medical marketing in promoting medical tourism in India. 2017;8(3).

[2] Kaur H, Kochar R, Management H, Gobindgarh M, Physician G. Growth of Medical Tourism in India: The Current Scenario. 2020; (5):181-6.

[3] Dr B Kalra. Gurgaon may become a medical tourism hub | India | Hindustan Times. [cited 2012 Jan 23]; Available from: https://www.hindustantimes.com/india/gurgaon-maybecome-a-medical-tourism-hub/story-

aAhfu4k9LwycrOpL4IX0jK.html

[4] Dawn SK, Pal S. Medical tourism in India: issues, opportunities and designing strategies for growth and development. 2011; 1(3).

[5] Mohammad Amiri NS. Medical tourism in India: current scenario. 2017; Vol.05 Issue (03). Available from: https://www.researchgate.net/publication/323990456\%0Ais sn: 2321-1784

[6] Agarwal A. Medical tourism in India and its advantages | Knowledge Tank. [cited 2017 Sep 27]; Available from: https://www.projectguru.in/publications/medical-tourism-inindia/

[7] Rai A. Globalization and Medical Tourism. Indian J Spat Science [Internet]. 2017; 5(February):14-23. Available from: http://www1.american.edu/ted/medical-tourism.htm

[8] (IITTM) II of T and TM. A study of problems and challenges faced by medical tourists visiting India. Indian Inst Tour Travel Manage. 2011.

[9] My MED Holiday. Why Medical Tourism in Thailand. 2016; (May). Available from: http://www.mymedholiday.com/country/thailand/article/39/ why-medical-tourism-in-thailand

[10] Cuevas Contreras T. An Approach to Medical Tourism on Mexico's Northern Border. Eurasia Bord Rev [Internet]. 2016; 6(1):45-62. Available from: http://www.usmcoc.org/papers-current/3-Desarrollo-

[11] Vindrola-Padros C. A Cautionary Tale: The 'New' Medical Tourism Industry in Argentina. Soma technics [Internet]. 2015; 5(1):69-87. Available from: http://www.euppublishing.com/doi/10.3366/soma.2015.014 8

[12] Gupta P, Pandey B, Hussain S, Kumar A, Sharma R. Challenges and Strengths of Medical Tourism in Delhi NCR. DU J Undergrad Research Innov. 2015; 1(2):230-51. 